Case report

\title{
Koro-like syndrome in a Jordanian male
}

N. Al-Hmoud

\section{Introduction}

The classic Koro syndrome is usually found in China and South-East Asia. The name Koro means "head of the turtle" in Malay and in Cantonese the condition is known as suk yeong, which means "shrinking penis". Other local languages in China and SouthEast Asia also have similar names for the condition. The classic syndrome in China and South-East Asia is culture-bound [I] and is characterized by the belief that:

- the penis is shrinking;

- it will disappear into the abdomen;

- it will cause death.

These beliefs are accompanied by an intense fear and by preventive manoeuvres such as tying, clamping or grasping the penis [2]. It occurs both in epidemic and sporadic forms and females may also have the syndrome. It is usually a relatively shortlived condition.

According to local cultural beliefs, disguised ghosts of the dead, who are deprived of genitals, will take away victims' genitals so as to come back to life again, and this induces great fear and panic [3].

There are various different considerations and suggestions regarding the basis and nature of the syndrome and no consensus. As it falls into no specific diagnostic category, it has been considered either a form of anxiety disorder, panic, depersonal- ization or castration fear, a form of hysteria, an obsessional disorder or a psychotic disorder $[2,4,5]$.

\section{Case report}

A 24-year-old single, male, Jordanian farmer was brought by his elder brother to the psychiatric outpatient clinic. He complained of a two-week history of difficulty in getting to sleep, apprehension, isolation, fearfulness and one night of strange behaviour. He asked for help to stop the shrinking of his penis and anxiously asked to have his genitalia checked. He was pulling at his penis to prevent it from being sucked into his pelvis. He had been kept awake the whole night with this condition.

The patient was the third of four brothers and had completed seventh grade education. His only medical history was surgery (orchidopexy) for torsion in the left testicle at the age of 19 years, after which he had become preoccupied by the idea that he might be infertile and that his manhood was defective. He had not sought medical advice about his fears.

A review of his sexual history revealed that the patient had heterosexual masturbational fantasies, had had no homosexual experience and his one sexual experience was with a prostitute 1 month prior to the onset of his symptoms, after which he was left

'Department of Psychiatry, Royal Medical Services, Amman, Jordan.

Received:12/01/99; accepted: 25/10/99

المجلة الصحية لشرق المتوسط، منظمة الصحة العالمية، المجلم الخامس، العلد ب 1999 19 
feeling guilty and embarrassed. His brother described him as shy, sensitive and dependent, with a small social circle. The family had no history of psychiatric illnesses.

Physical examination, including the genitalia, was unremarkable and showed no clinical signs of organicities. The patient was bewildered, sweating, tremulous and caught restlessly at his crotch. He was convinced that his penis was gradually shrinking and would disappear into his abdomen. In great fear he stated that he preferred death to such a fate. There were no psychotic features. He was of average intelligence and brain magnetic resonance imaging was normal.

He was diagnosed as having a generalized anxiety disorder and panic. He was treated as an outpatient with the following medications:

- imipramine: $25 \mathrm{mg} /$ day gradually increased to $75 \mathrm{mg} /$ day over 3 weeks;

- alprazolam: $1 \mathrm{mg} /$ day taken as $0.5 \mathrm{mg}$ tablet twice daily.

In addition, he was given supportive psychotherapy and behavioural therapy.

He was asymptomatic in 3 months and at a 10-month follow-up he was completely back to normal and had ceased taking medication.

\section{Discussion}

Sporadic cases of Koro-like syndrome have been reported in non-Chinese cultures and countries other than China and South-East Asia (European, African, North American, Middle Eastern countries and India) [2,6].

These cases were usually part of, or accompanied by, variant disorders $[2,7,8,9]$ and almost all were a non-classical, incomplete form of the syndrome (as in the case of this patient, because rather than being in fear of impending death, he preferred death to the disappearance of his genitals).

Despite a cultural heritage in Jordan that believes in ghosts and demons, and in their power to manipulate and influence behaviour (occasionally including sexual potency and the ability to inflict harm), these ghosts are not believed capable of taking away a person's genitals. Generally, Arab culture has little relation to Chinese and South-East Asian cultures, particularly in this type of belief.

In this case the patient was preoccupied with a misconception about his fertility and sexual potency after his testicular operation. Added to this were his feelings of guilt after a sexual contact with a prostitute. It is presumed that the symptoms were an expression of his premorbid sexual status and experience $[3,5]$.

\section{References}

1. Tseng WS et al. A sociocultural study of Koro epidemics in Guangdong, China. American journal of psychiatry, 1988, 145:1538-43.

2. Berrios GE, Morley SJ. Koro-like symptom in a non-Chinese subject. British journal of psychiatry, 1984, 145:331-4.
3. Rubin RT. Koro (Shook yang). A culturebound psychogenic syndrome. In: Friedmann CTH, Faguet RA, eds. Extraordinary disorders of human behavior. New York, Plenum, 1982.

4. Charaborty PK. Koro: a peculiar anxiety neurosis (a case report). Indian journal of psychiatry, 1982, 24:192-3. 
5. Yap PM. Koro, a culture-bound depersonalization syndrome. British journal of psychiatry, 1965, 111:43-50.

6. Montaser H. Koro-like symptom in a Saudi patient. Arab journal of psychiatry, 1992, 1:56.

7. Tantam D, Appleby L, Duncan A. Psychiatry for the developing world. London, Gaskell, 1996.
8. Dow TW, Silver D. A drug-induced Koro syndrome. Journal of the Florida Medical Association, 1973, 60:32-3.

9. Ang PC, Weller MP. Koro and pychosis. British journal of psychiatry, 1984, 145: 335.

The implementation of national mental health programmes with the strategy of integration of mental health into primary health care continued in many countrics of the Region. In Bahrain and the Islamic Republic of Iran, the integrated system of mental health services in primary health care is functioning well. In Iraq, Jordan, Oman, Saudi Arabia, Sudan and the Syrian Arab Republic, training of general practitioners/primary health care physicians in mental health is continuing.

Source: The Work of WHO in the Eastern Mediterranean Region. Annual Report of the Regional Director, 1 January - 31 December 1998, Page 74 World Health Organization, Regional Office for the Eastern Mediterranean, Alexandria, 1999.

المجلة الصحية لشرق المتوسط، منظمة الصحة العالمية ، المجلد الخامس، العدد ب ، 1999 